\title{
Caracterización molecular de Escherichia coli resistente a antibióticos aislada de mastitis bovina en Michoacán, México
}

\section{Molecular characterization of antibiotic resistant Escherichia coli isolated from bovine mastitis in Michoacán, México}

\author{
Rafael Jiménez Mejía*, Luis Fernando Gudiño Sosa, José Antonio Aguilar López, Pedro Damián Loeza Lara
}

\begin{abstract}
RESUMEN
En el presente estudio se describen los patrones de resistencia a antibióticos de $E$. coli aislada de mastitis bovina, así como la presencia de genes de virulencia y de resistencia. A partir muestras de leche obtenidas de vacas con mastitis se aislaron e identificaron a nivel bioquímico y molecular cepas de $E$. coli, a las cuales se les analizó el perfil de resistencia a antibióticos y mediante PCR se investigó la presencia de genes de virulencia, de resistencia a antibióticos beta-lactámicos, tetraciclina, estreptomicina y quinolonas; así como la presencia de integrones clase 1. El análisis genético reveló que $11.8 \%$ de los aislados de $E$. coli presentaron el gen de virulencia que codifica para la intimina (eaeA). Por otro lado, todas las $E$. coli fueron resistentes a uno o más antibióticos, con alta frecuencia de resistencia para tetraciclina, ampicilina y cefalotina. Además, el $73.5 \%$ fueron resistentes a tres o más antibióticos. De 11 genes de resistencia analizados, se confirmó la presencia de siete, distribuidos en el $79.4 \%$ de los aislados bacterianos. De los cuales, blacтх-м se encontró en 16 aislados, tetB en 11, tetA, strA y strB en 9, qnrB en cuatro y blaтем en un solo aislado. También, en el $5.9 \%$ de los aislados de $E$. colí se identificó la presencia de integrones clase 1 . En conclusión, se encontraron elevados índices de resistencia en las $E$. coli aisladas de mastitis bovina. Estas bacterias contienen genes de virulencia relacionados a patógenos de humano; también llevan genes de resistencia a beta-lactámicos, tetraciclina, estreptomicina y quinolonas.
\end{abstract}

PALABRAS CLAVE: Mastitis bovina, E. coli, Resistencia a los antibióticos, Genes de virulencia, PCR.

\begin{abstract}
In the present study the antibiotic resistance patterns of $E$. coli isolated from bovine mastitis, as well as the presence of Extended-spectrum $\beta$-lactamases (ESBL), tetracycline, streptomycin, and quinolone resistance genes were analyzed. From mastitic cows, milk samples were obtained, of which $E$. coli were isolated and identified biochemically and confirmed at the molecular level. Genetic analysis revealed that $\mathbf{1 1 . 8} \%$ of the $E$. coli contained a virulence gene encoding intimin (eaeA). All $E$. coli were resistant to one or more antibiotics, with higher rates of resistance to tetracycline, ampicillin, and cephalothin. In addition, $73.5 \%$ of $E$. coli were resistant to three or more antibiotics. Of eleven resistance genes analyzed, seven were detected in $79.4 \%$ of the bacterial isolates. Of these, blactx-M was found in 16 isolates, tetB in 11, tetA, strA and strB in nine, qnrB in four, and blatem in one isolate. About $5.9 \%$ of the $E$. coli isolates carried class 1 integron integrase gene. In conclusion, a high prevalence of antibiotic resistance in $E$. coli isolated from bovine mastitis was identified. The bacteria also harbor a virulence gene related to human pathogens and genes conferring resistance to beta-lactam antibiotics, tetracycline, streptomycin, and quinolones.
\end{abstract}

KEY WORDS: Bovine mastitis, E. coli, Antibiotic resistance, Virulence genes, PCR.

Recibido el 17 de agosto de 2016. Aceptado el 22 de noviembre de 2016.

Universidad de La Ciénega del Estado de Michoacán de Ocampo. Avenida Universidad \# 3000. Colonia Lomas de la Universidad. 59103 Sahuayo, Michoacán. México.

*Autor de correspondencia: rjimenez@ucienegam.edu.mx 


\section{INTRODUCCIÓN}

La mastitis bovina es una enfermedad compleja con alta prevalencia a nivel mundial, por lo que ésta continua siendo un problema para la industria lechera, debido a las pérdidas económicas por la reducción en la producción de leche, desecho del producto, descarte temprano de animales enfermos y servicios veterinarios ${ }^{(1)}$. Se han asociado a la enfermedad diversas especies de microorganismos, sin embargo, solo un grupo reducido de especies bacterianas son los agentes causales más comunes de la enfermedad, que de acuerdo con su origen se clasifican como patógenos contagiosos 0 ambientales $^{(2)}$. Los primeros, son aquellos adaptados a sobrevivir dentro de la glándula mamaria y pueden causar infecciones asintomáticas. Los principales miembros de este grupo son Staphylococcus aureus, Streptococcus agalactiae y Mycoplasma $\mathrm{spp}^{(2,3)}$. Por otro lado, los patógenos ambientales son oportunistas y no están adaptados a sobrevivir en la glándula mamaria. Este grupo incluye a Streptococcus spp no agalactiae, Enterococcus spp, Staphylococus coagulasanegativos y bacterias coliformes. De estos últimos el patógeno más importante es Escherichia co/ $\AA^{2,3}$.

Generalmente, E. coli es considerada una bacteria no patógena que habita en el intestino de humano y animales. No obstante, se han descrito varios patotipos clasificados como patógenos intestinales o extraintestinales ${ }^{(4)}$. Para el caso de $E$. coli causante de mastitis, a la fecha no se han identificado cepas 0 factores de virulencia específicos, pero se ha propuesto que forman un nuevo patotipo denominado Mammary Pathogenic E. coli (MPEC) $)^{(5)}$. Sin embargo, se ha observado gran diversidad tanto genética como en los factores de virulencia entre esas bacterias ${ }^{(6,7)}$. De estos últimos factores, muchos son comunes con los patotipos de humanos e incluyen toxinas, adhesinas, producción de cápsula, la habilidad para resistir el complemento sérico y sistemas de adquisición de hierro ${ }^{(7-9)}$.

Entre las estrategias para el control de la mastitis, la principal es la terapia con antibióticos, aunque frecuentemente el tratamiento falla debido a la creciente resistencia bacteriana a dichos compuestos $^{(10)}$. Además, el uso indiscriminado de antibióticos para el tratamiento de infecciones y como promotores de crecimiento en animales, ha favorecido el desarrollo de resistencia bacteriana, que puede ser transmitida a patógenos de animales o humanos ${ }^{(11)}$. Por esto, el ganado bovino es considerado un reservorio importante de bacterias que llevan genes de resistencia para antibióticos beta-lactámicos de espectro extendido, tetraciclinas, quinolonas, aminoglucósidos, entre otros ${ }^{(10)}$. Por lo anterior, la mastitis bovina es considerada un problema de salud pública debido a la contaminación de la leche con bacterias patógenas resistentes a los antibióticos $^{(12)}$.

Entre los principales mecanismos de resistencia bacteriana a los antibióticos se encuentran la producción de beta-lactamasas de espectro extendido (BLEE), especialmente en bacterias Gram negativas. Las principales familias de BLEE son las de tipo CTX-M, TEM, CMY, SHV y OXA ${ }^{(13,14)}$. De acuerdo con lo anterior, se ha observado incremento en la detección de beta-lactamasas en bacterias de origen animal(12). También, la resistencia a antibióticos en bacterias Gram negativas incluye la presencia de sistemas de expulsión, como los codificados por los genes tetA-G, asociados con resistencia a tetraciclina ${ }^{(15)}$. De igual forma, la resistencia puede ser debida a la presencia de enzimas que modifican e inactivan a los antibióticos, como aquellas que confieren resistencia a estreptomicina codificada por los genes strA-str $B^{16)}$. Frecuentemente los genes de resistencia están asociados a plásmidos conjugativos e integrones, que son los principales elementos involucrados en la diseminación de la resistencia a antibióticos entre bacterias Gram negativas ${ }^{(17)}$.

La región occidente de Michoacán, México, es una zona productora de leche muy importante, sin embargo, a la fecha no hay información sobre los principales patógenos causantes de la mastitis bovina, así como de los perfiles fenotípicos y genotípicos de su resistencia a los antibióticos. Por tanto, el objetivo del presente trabajo fue estudiar los patrones de resistencia a los antibióticos de $E$. coli aisladas de mastitis bovina, analizar la prevalencia de genes de virulencia y de resistencia para beta-lactámicos, tetraciclina, estreptomicina y quinolonas, así como su asociación con integrones clase 1. 


\section{MATERIAL Y MÉTODOS}

\section{Detección de mastitis y toma de muestras}

Este trabajo se desarrolló durante 2013, como parte de un programa regional para el estudio de la mastitis en el occidente de Michoacán, México. En el estudio se incluyeron nueve establos con un tamaño de 7 a 64 vacas. La mastitis se detectó mediante la aplicación de la prueba de California (PC) (Sanfer, México), siguiendo las instrucciones del fabricante. La PC se realizó en los cuatro cuartos de cada vaca, y de los cuartos que dieron positivo a la prueba se colectó una muestra de $30 \mathrm{ml}$ de leche en tubos estériles. Previo a la colecta de la muestra, los cuartos se desinfectaron con algodón humedecido con alcohol al $70 \%$, desechando los primeros chorros de leche. Las muestras colectadas se transportaron a $4{ }^{\circ} \mathrm{C}$ en hielo al laboratorio y se procesaron el mismo día.

\section{Aislamiento de E. coli}

De cada una de las muestras se inocularon 100 $\mu$ en agar MacConkey (Difco, USA) y se incubaron por $24 \mathrm{~h}$ a $37^{\circ} \mathrm{C}$. A partir de las muestras en que se observó crecimiento, se seleccionó al azar una colonia fermentadora de lactosa para su análisis, la cual fue estriada en agar Eosina Azul de Metileno (Difco, USA) y se le realizó tinción de Gram. De estas últimas se seleccionaron 34 colonias típicas de $E$. coli y se identificaron bioquímicamente de acuerdo a la literatura(18). Las principales pruebas que se realizaron fueron fermentación de glucosa y lactosa, así como producción de gas y $\mathrm{H}_{2} \mathrm{~S}$ en agar Kligler con Hierro, IMViC (indol, rojo de metilo, VogesProskauer y citrato), oxidasa, catalasa, ureasa y producción de fluorescencia en medio EC-MUG.

\section{Extracción de ADN}

El ADN se preparó a partir de $500 \mu \mathrm{l}$ de un cultivo de toda la noche. Las células se centrifugaron a 13,000 rpm por 2 min. Después, el sobrenadante se descartó y las células se resuspendieron en $1 \mathrm{ml}$ de agua destilada estéril y se llevaron a ebullición por 10 min. La mezcla resultante se centrifugó por 5 min a 13,000 rpm y el sobrenadante se utilizó directamente como DNA molde o se almacenó a -20 ${ }^{\circ} \mathrm{C}$ hasta su uso(19).

\section{Análisis molecular de los aislados de E. coli}

Para confirmar la identidad de los aislados se amplificaron fragmentos de los genes uidA y lacZ con los primers uidA-F/uidA-R y lacZ-F/lacZ-R, respectivamente (Cuadro 1 ). Las amplificaciones por PCR se realizaron de acuerdo a la metodología descrita ${ }^{(20)}$. Por otro lado, mediante PCR multiplex con los primers enlistados en el Cuadro 1, se analizó la presencia de genes de virulencia característicos de las dos principales variantes de $E$. coli patógenas de humanos, E. coli enteropatógena (EPEC) y E. coli enterohemorrágica (EHEC). Los genes analizados fueron eaeA, que codifica para la intimina y es común a EPEC y EHEC, bfpA, que codifica para la pilina del pilus tipo IV de EPEC y stx2, que codifica para la toxina Shiga tipo 2 de EHEC. Las reacciones de PCR se realizaron como se describió previamente ${ }^{(21)}$.

Para la detección de los genes de resistencia en E. coli, los extractos de ADN total se utilizaron para amplificar por PCR fragmentos de los genes blateM, blasHv, blactx-M, bla ${ }_{\mathrm{CMY}}$ y bla ${ }_{\mathrm{OXA}}{ }^{(22)}$. También, se amplificaron los genes de resistencia a tetraciclina tet $A$ y tet $B$ con primers descritos previamente ${ }^{(22,23)}$, así como genes de resistencia a estreptomicina strA y $\operatorname{str}^{(24)}$ y de resistencia a quinolonas qnrA y $q n r B^{(25)}$. Los genes se seleccionaron debido a los altos índices de resistencia de las $E$. coli a los antibióticos beta-lactámicos, tetraciclina y estreptomicina. Además, los genes de resistencia se han asociado frecuentemente a integrones clase 1 , por lo cual se analizó la presencia del gen que codifica para la integrasa intI1 $1^{(26)}$. Las características de las secuencias de los primers se enlistan también en el Cuadro 1. En general, las mezclas de reacción para las amplificaciones se realizaron en un volumen de $25 \mu$ conteniendo: 1X de Master mix (Promega, USA), $0.5 \mu \mathrm{M}$ de cada primer y $1 \mu \mathrm{l}$ de extracto total de ADN. Las reacciones de PCR se realizaron en un termociclador C1000 (Bio-Rad, México). La amplificación se inició con un ciclo de desnaturalización a $95{ }^{\circ} \mathrm{C}$ por 5 min seguido de 35 ciclos a las siguientes temperaturas: desnaturalización a $95^{\circ} \mathrm{C}$ por $40 \mathrm{seg}$, alineamiento a la temperatura indicada en el Cuadro 1 para cada par de oligonucleótidos por 
$40 \mathrm{seg}$, extensión a $72{ }^{\circ} \mathrm{C}$ por 1 min y un ciclo final de extensión a $72{ }^{\circ} \mathrm{C}$ por $5 \mathrm{~min}$. Los fragmentos amplificados se separaron por electroforesis en geles de agarosa al $1 \%$, se tiñeron con bromuro de etidio y se visualizaron en un fotodocumentador Gel Doc Universal Hood II (Bio-Rad, México).

Cuadro 1. Oligonucleótidos usados con su temperatura de alineamiento $(\mathrm{Tm})$ y el fragmento amplificado esperado

\begin{tabular}{|c|c|c|c|c|}
\hline Nombre & Secuencia $5^{\prime} \rightarrow 3^{\prime}$ & $\operatorname{Tm}\left({ }^{\circ} \mathrm{C}\right)$ & Fragmento amplificado $(\mathrm{pb})$ & Referencia \\
\hline lacZ-F & ATGAAAGCTGGCTACAGGAAGGCC & \multirow{2}{*}{58} & \multirow{2}{*}{264} & \multirow{2}{*}{ (20) } \\
\hline lacZ-R & GGTTTATGCAGCAACGAGACGTCA & & & \\
\hline uidA-F & AAAACGGCAAGAAAAAGCAG & \multirow{2}{*}{58} & \multirow{2}{*}{147} & \multirow{2}{*}{ (20) } \\
\hline uidA-R & ACGCGTGGTTACAGTCTTGCG & & & \\
\hline TEM-F & ATAAAATTCTTGAAGACGAAA & \multirow{2}{*}{50} & \multirow{2}{*}{1080} & \multirow{2}{*}{ (22) } \\
\hline TEM-R & GACAGTTACCAATGCTTAATC & & & \\
\hline SHV-F & TTATCTCCCTGTTAGCCACC & \multirow{2}{*}{50} & \multirow{2}{*}{795} & \multirow{2}{*}{ (22) } \\
\hline SHV-R & GATTTGCTGATTTCGCTCGG & & & \\
\hline OXA-F & TCAACTTTCAAGATCGCA & \multirow{2}{*}{57} & \multirow{2}{*}{591} & \multirow{2}{*}{ (22) } \\
\hline OXA-R & GTGTGTTTAGAATGGTGA & & & \\
\hline CTX-M-F & CGCTTTGCGATGTGCAG & \multirow{2}{*}{52} & \multirow{2}{*}{550} & \multirow{2}{*}{$(22)$} \\
\hline CTX-M-R & ACCGCGATATCGTTGGT & & & \\
\hline CMY-F & GACAGCCTCTTTCTCCACA & \multirow{2}{*}{50} & \multirow{2}{*}{1000} & \multirow{2}{*}{$(22)$} \\
\hline CMY-R & TGGAACGAAGGCTACGTA & & & \\
\hline qnrA-F & ATTTCTCACGCCAGGATTTG & \multirow{2}{*}{52} & \multirow{2}{*}{516} & \multirow{2}{*}{$(25)$} \\
\hline qnrA-R & GATCGGCAAAGGTTAGGTCA & & & \\
\hline qnrB-F & GATCGTGAAAGCCAGAAAGG & \multirow{2}{*}{53} & \multirow{2}{*}{469} & \multirow{2}{*}{$(25)$} \\
\hline qnrB-R & ACGATGCCTGGTAGTTGTCC & & & \\
\hline strA-F & CTTGGTGATAACGGCAATTC & \multirow{2}{*}{53} & \multirow{2}{*}{548} & (24) \\
\hline strA-R & CCAATCGCAGATAGAAGGC & & & $(24)$ \\
\hline strB-F & ATCGTCAAGGGATTGAAACC & 53 & 500 & (21) \\
\hline strB-R & GGATCGTAGAACATATTGGC & 50 & 509 & $(24)$ \\
\hline tetA-F & GGCCTCAATTTCCTGACG & 56 & 372 & (23) \\
\hline tetA-R & AAGCAGGATGTAGCCTGTGC & 00 & 012 & $(\langle 0)$ \\
\hline tetB-F & СCTCAGCTTCTCAACGCGTG & 50 & 632 & (20) \\
\hline tetB-R & GCACCTTGCTCATGACTCTT & 56 & 633 & (22) \\
\hline bfpA-F & GGAAGTCAAATTCATGGGGGTAT & 55 & 305 & \\
\hline bfpA-R & GGAATCAGACGCAGACTGGTAGT & 55 & 305 & (21) \\
\hline$s t \times 2-F$ & ATCCTATTCCCGGGAGTTTACG & 55 & 587 & (21) \\
\hline$s t \times 2-R$ & GCGTCATCGTATACACAGGAGC & 35 & 501 & $(21)$ \\
\hline eae-F & TCAATGCAGTTCCGTTATCAGTT & 55 & 501 & (21) \\
\hline eae- $R$ & GTAAAGTCCGTTACCCCAACCTG & Ju & (1) & $(<1)$ \\
\hline Intl1-F & GGGTCAAGGATCTGGATTTCG & 62 & 182 & \\
\hline Intl1-R & ACATGCGTGTAAATCATCGTCG & 62 & 483 & (26) \\
\hline
\end{tabular}




\section{Pruebas de resistencia a los antibióticos}

Las pruebas de susceptibilidad se realizaron por ensayos de difusión en disco en agar Mueller-Hinton (Difco, USA), para lo cual se preparó una suspensión bacteriana equivalente a la turbidez del tubo 0.5 de la escala de McFarland (1-2 x $\left.10^{8} \mathrm{UFC} / \mathrm{ml}\right)$. Después, se distribuyeron $200 \mu$ le la suspensión bacteriana sobre la superficie del agar Müeller-Hinton (Difco, USA). Posteriormente, se colocaron los multidiscos para Gram negativos II (Bio-Rad, México), con los siguientes antibióticos a las cantidades indicadas: amikacina $(30 \mu \mathrm{g})$, ampicilina $(10 \mu \mathrm{g})$, levofloxacina $(5 \mu \mathrm{g})$, cefalotina $(30 \mu \mathrm{g})$, cefotaxima (30 $\mu \mathrm{g})$, ceftriaxona $(30 \mu \mathrm{g})$, cloramfenicol $(30 \mu \mathrm{g})$, gentamicina $(10 \mu \mathrm{g})$, netilmicina $(30 \mu \mathrm{g})$, nitrofurantoina $(300 \mu \mathrm{g})$, cefepima $(30 \mu \mathrm{g})$ y trimetoprim-sulfametoxazol $(25 \mu \mathrm{g})$. Las zonas de inhibición se midieron, y de acuerdo a las instrucciones del fabricante los aislados se clasificaron como resistentes (R), intermedios (I) o sensibles (S). La resistencia a tetraciclina, kanamicina y estreptomicina (Sigma Aldrich, México) se analizó mediante el método de microdilución y se interpretó de acuerdo a los criterios del CLSI ${ }^{(27)}$. Los aislados se clasificaron como resistentes si las concentraciones mínimas inhibitorias (CIM) fueron $\geq 16 \mu \mathrm{g} / \mathrm{ml}$ para tetraciclina, $\geq 25 \mu \mathrm{g} / \mathrm{ml}$ para kanamicina y $\geq 32 \mu \mathrm{g} / \mathrm{ml}$ para estreptomicina.

\section{RESULTADOS}

De acuerdo a la PC, la prevalencia de mastitis subclínica en el área estudiada fue de $49 \%$, ya que 148 de 302 vacas dieron positivo a la prueba en al menos uno de los cuartos. En total se colectaron 120 muestras de leche de las vacas con mastitis, 28 no se pudieron obtener por dificultades técnicas durante la toma de muestras. De las muestras colectadas, en 51 (42.5\%) se obtuvo crecimiento en agar MacConkey, de éstas se seleccionó una colonia representativa fermentadora de lactosa y se confirmó como Gram negativa. Treinta y cuatro $(66.7 \%)$ colonias fermentadoras de lactosa se identificaron bioquímicamente como $E$. coli y en todas ellas se amplificaron fragmentos de los genes uidA y lacZ (Figura $1 \mathrm{~A}$ ). Además, en 4/34 (11.8\%) aislados de $E$. coli, se detectó el gen de virulencia para la intimina (eaeA), pero en ningún aislado se identificaron los genes de virulencia bfpA o stx2 (Figura 1B).

Figura 1. Confirmación molecular de $E$. coli y detección de genes de virulencia. A) $\mathrm{M}$, marcador de ADN 1 Kb plus; 1 , control positivo para lacZ/uidA (EPEC); 2-10, aislados representativos positivos para lacZ/uidA genes. B) M, marcador de ADN $1 \mathrm{~Kb}$ plus; 1, control positivo para eaeA/bfpA (EPEC); 2, control positivo para eaeA/stx2 (EHEC); 3, aislado negativo para eaeA/stx2/bfpA; 4 y 5 , aislados representativos positivos para eaeA

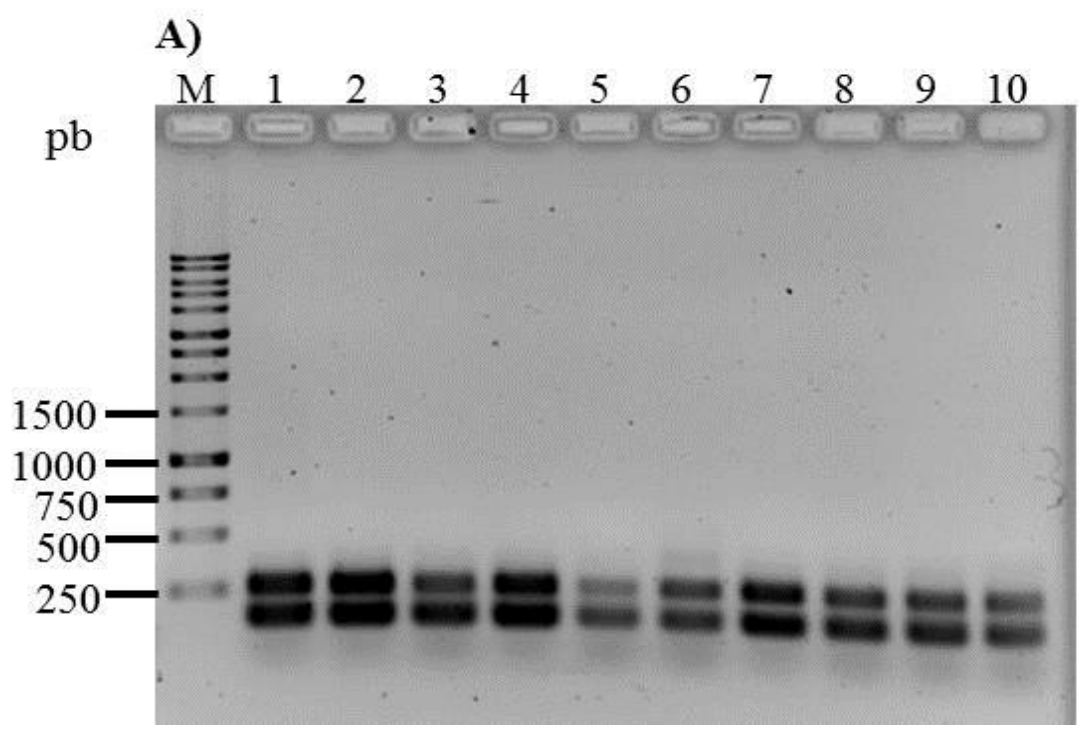

B)

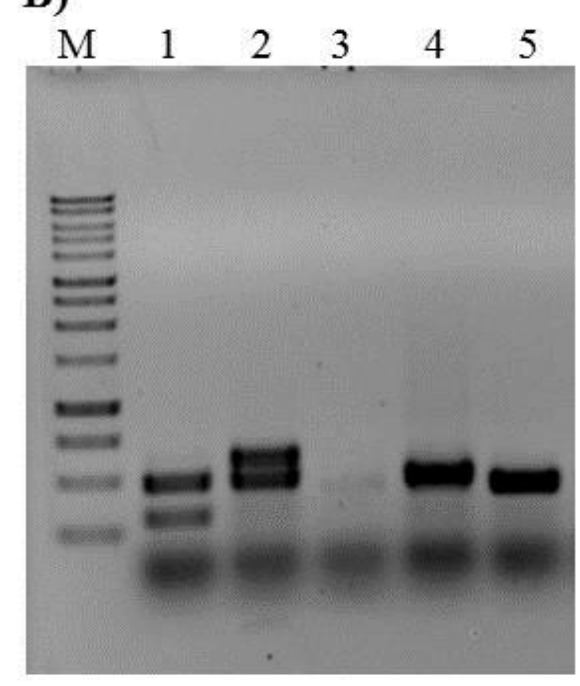


Cuadro 2. Perfiles de susceptibilidad a los antibióticos de las 34 E. coli aisladas de mastitis bovina

\begin{tabular}{lccr}
\hline & \multicolumn{3}{c}{ Número de aislados (\%) } \\
Antibiótico & $2(5.9)$ & $7(20.6)$ & $25(73.5)$ \\
\hline Amikacina (Ak) & $26(76.5)$ & $6(17.6)$ & $2(5.9)$ \\
Ampicilina (Am) & $2(5.9)$ & $1(2.9)$ & $31(91.2)$ \\
Levofloxacina (Lev) & $25(73.5)$ & $6(17.6)$ & $3(8.8)$ \\
Cefalotina (Cf) & $3(8.8)$ & $22(64.7)$ & $9(26.5)$ \\
Cefotaxima (Ctx) & $4(11.8)$ & $16(47)$ & $14(41.2)$ \\
Ceftriaxona (Cro) & $4(11.8)$ & $9(26.4)$ & $21(61.8)$ \\
Cloranfenicol (Cl) & $4(11.8)$ & $2(5.9)$ & $28(82.4)$ \\
Gentamicina (Ge) & $4(11.8)$ & $1(2.9)$ & $29(85.3)$ \\
Netilmicina (Net) & $12(35.3)$ & $18(52.9)$ & $4(11.8)$ \\
Nitrofurantoína (Nf) & $2(5.9)$ & $3(8.8)$ & $29(85.3)$ \\
Cefepima (Fep) & $1(2.9)$ & $0(0)$ & $33(97)$ \\
Trimetoprima-Sulfametoxazol (Stx) & Sensibles \\
Tetraciclina (Te) & $30(88.2)$ & $0(0)$ & $4(11.8)$ \\
Kanamicina (Km) & $4(11.8)$ & $0(0)$ & $30(88.2)$ \\
Estreptomicina (Stp) & $13(38.2)$ & $0(0)$ & $21(61.8)$ \\
\hline
\end{tabular}

\section{Perfiles de resistencia a los antibióticos}

Los ensayos de susceptibilidad a los antimicrobianos de las $E$. coli $(\mathrm{n}=34)$ revelaron que todas fueron resistentes a uno o más antibióticos (Cuadro 2). Los compuestos a los cuales mostraron mayores índices de resistencia fueron a tetraciclina (88.2 \%), ampicilina (76.5 \%) y cefalotina (73.5 \%). Índices de resistencia menores que van de 38.2 al $2.9 \%$ se observaron en los restantes 12 antibióticos. Además, se observó resistencia intermedia principalmente para cefotaxima (64.7\%), nitrofurantoína (52.9\%) y ceftriaxona (47\%). Por otro lado, se observaron altos índices de susceptibilidad para trimetoprimsulfametoxazol (97\%), levofloxacina (91.2\%), kanamicina (88.2 \%), cefepima (85.3\%), netilmicina (85.3\%), gentamicina (82.4\%), amikacina (73.5\%), cloranfenicol y estreptomicina $(61.8 \%)$, respectivamente. Se observaron 26 patrones de resistencia distintos entre los 34 aislados de $E$. coli, siendo los patrones observados con mayor frecuencia, los de resistencia a tetraciclina y ampicilina-cefalotina-nitrofurantoínatetraciclina con cuatro aislados cada uno. Adicionalmente, 25 (73.5 \%) aislados se clasificaron como multirresistentes, ya que toleraron tres o más
Cuadro 3. Patrones de resistencia de las E. coli

\begin{tabular}{lc}
\hline Perfil de resistencia* & No. de aislados (\%) \\
\hline Te & $4(11.8)$ \\
AmCf & $1(2.9)$ \\
AmTe & $2(5.9)$ \\
CfTe & $1(2.9)$ \\
KmTe & $1(2.9)$ \\
AmCfGe & $1(2.9)$ \\
AmCfNf & $1(2.9)$ \\
AmGeTe & $1(2.9)$ \\
CfStpTe & $1(2.9)$ \\
KmStpTe & $1(2.9)$ \\
AmCfNetTe & $1(2.9)$ \\
AmCfNfTe & $4(11.8)$ \\
AmCfStpTe & $2(5.9)$ \\
AmCfNetTe & $1(2.9)$ \\
AmCfNetStpTe & $1(2.9)$ \\
AmCfNfStpTe & $1(2.9)$ \\
AmCfCINfTe & $1(2.9)$ \\
AmCfLevStpTe & $1(2.9)$ \\
AmCfCroNfStpTe & $1(2.9)$ \\
AmCfGeNetStpTe & $1(2.9)$ \\
AmCfKmNfStpTe & $1(2.9)$ \\
AkAmCfCtxFepNfTe & $1(2.9)$ \\
AmCfCroCtxFepNfTe & $1(2.9)$ \\
AmCfClCroCtxGeStpTe & $1(2.9)$ \\
AkAmCfClCroNfStpTe & $1(2.9)$ \\
AmCfCIKmLevStpSxtTe & $1(2.9)$ \\
\hline
\end{tabular}

*Abreviaciones, Ak amikacina, Am ampicilina, Lev levofloxacina, Cf cefalotina, Ctx cefotaxima, Cro ceftriaxona, Cl cloranfenicol, Ge gentamicina, Net netilmicina, Nf nitrofurantoína, Fep cefepima, Sxt trimetoprima-sulfametoxazol, Te tetraciclina, Km kanamicina, Stp estreptomicina.

antibióticos diferentes, de los cuales, 12 (35.3\%) presentaron resistencia de 5 a 8 antibióticos (Cuadro $3)$.

\section{Presencia de genes de resistencia $e$ integrones clase 1 en E. coli}

De los 11 genes de resistencia analizados, se logró detectar la presencia de 7 en $27(79.4 \%) E$. coli (Figura 2A). El más frecuente fue bla presente en 16 (47\%) aislados, seguido por tetB en 11 (32.3 \%), tet $A$, strA, strB en 9 (26.5\%), respectivamente; $q n r B$ en 4 aislados y blatem en 1 (2.9 \%) aislado (Cuadro 4). Adicionalmente, los 
Figura 2. Amplificación por PCR de genes de resistencia y de integrasa tipo 1. A) M, marcador de ADN $1 \mathrm{~Kb}$ plus; 1 y 2, aislados positivos para blaстх-м; 3 , aislado positivo para blaтем; 4 y 5 , aislados positivos para qnrB; 6 y 7 , aislados positivos para tetB; 8 y 9 , aislados positivos para tetA; 10, aislado positivo strA; 11 , aislado positivo para strB. B) M, marcador de ADN $1 \mathrm{~Kb}$ plus; 1 y 2 , aislados positivos para int 11

A)

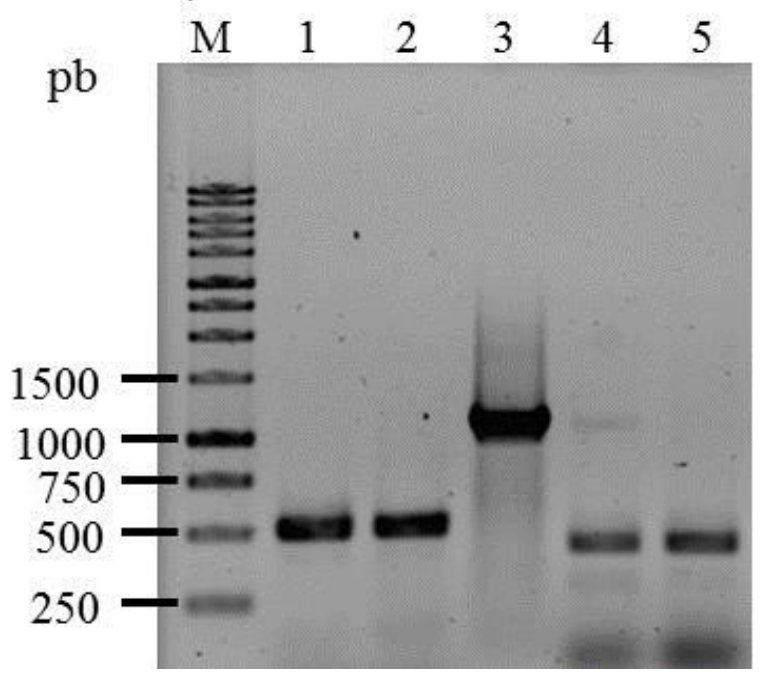

B)

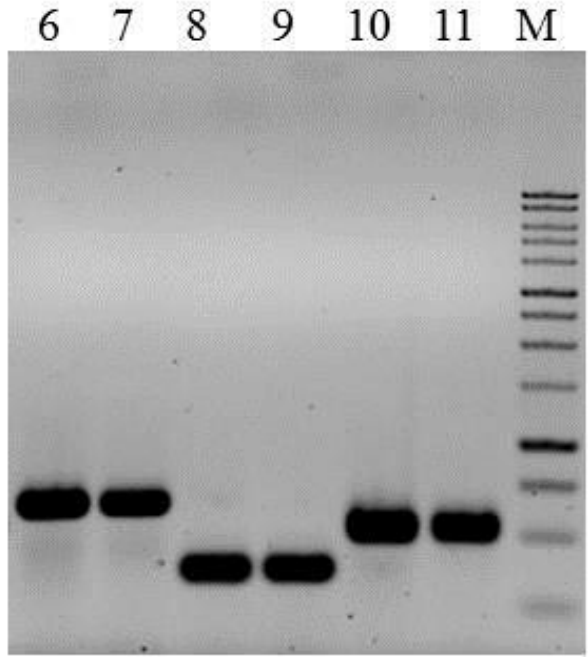

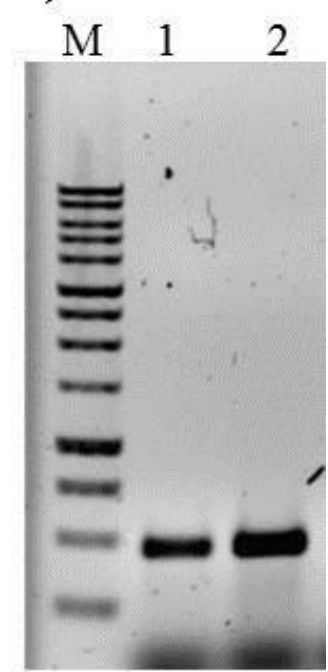

Cuadro 4. Perfil de genes de resistencia detectados en E. coli

\begin{tabular}{|c|c|}
\hline Genes de resistencia & No. de aislados (\%) \\
\hline Ninguno & $7(20.6)$ \\
\hline$b l a_{\text {CTX-M }}$ & $6(17.6)$ \\
\hline tet $A$ & $3(8.8)$ \\
\hline tet $B$ & $3(8.8)$ \\
\hline$b l a_{\mathrm{CTX}-\mathrm{M}}, q n r B$ & $1(2.9)$ \\
\hline$b l a_{\text {CTX-м }}$, tet $A$ & $1(2.9)$ \\
\hline$b l a_{\text {CTX-м }}$, tetB & $2(5.9)$ \\
\hline$b l a_{\text {CTX-M }}, q n r B$, tetA & $2(5.9)$ \\
\hline$b l a_{\text {СТX-м }}$, str $A$, strB, tet $A$ & $2(5.9)$ \\
\hline$b l a_{\text {CTX-M }}, \operatorname{str} A, \operatorname{str} B$, tetB & $2(5.9)$ \\
\hline$b l a_{\mathrm{TEM}}, q n r B, s t r A, s t r B, \operatorname{tet} A$ & $1(2.9)$ \\
\hline tet $B, \operatorname{str} A, \operatorname{str} B$ & $4(11.8)$ \\
\hline Total & $34(100)$ \\
\hline
\end{tabular}

genes de resistencia identificados se presentaron solos (12 aislados) o en diferentes combinaciones (15 aislados). De estos últimos, 10 aislados positivos para blacтх-м presentaron seis arreglos distintos con los genes strA, str $A$, tet $A$, tetB y qnrB; mientras que el arreglo tetB-strA-str $B$ se encontró en cuatro aislados y blat:eM-tetA-strA-strB en un aislado. Sin embargo, de las 34 E. coli, solo dos (5.9\%) aislados multirresistentes contienen el gen de la integrasa para integrones clase 1 (Figura 2B). De los cuales, uno presentó el gen tet $B$, mientras que en el segundo se identificó el arreglo blaCTX-м-tetA-strAstrB.

\section{DISCUSIÓN}

La mastitis bovina es la enfermedad más importante del ganado bovino a nivel mundial. Su prevalencia, tipo de microorganismos causales y sus características son variables de un lugar a otro. $E$. coli es un patógeno ambiental importante causante de mastitis; cuando esta bacteria infecta la glándula mamaria se muestran síntomas de inflamación, reducción en la producción y cambios físico-químicos en la leche ${ }^{(28)}$.

Las $E$. coli aisladas en este trabajo pertenecen a 34 muestras distintas, lo cual representa un $28.3 \%$ de muestras positivas para esta bacteria. Datos similares en la frecuencia de aislamiento de $E$. 
coli han sido reportados ${ }^{(29)}$, donde el $27.2 \%$ de las muestras colectadas de vacas con mastitis fueron positivas para $E$. coli. Además, en cuatro de las $E$. coli se detectó el gen de virulencia de la intimina, aunque no se detectaron los genes bfpA o sxt2. Lo anterior sugiere que esas bacterias pueden ser $E$. coli enteropatógena atípicas (aECEP) o $E$. coli enterohemorrágica (ECEH) con otra variante del gen $s t x^{(4)}$. Sin embargo, el repertorio de genes de virulencia analizado en este trabajo fue limitado y se requieren más estudios para estudiar el catálogo completo de genes en las $E$. coli causantes de mastitis. En este sentido, se sabe que el ganado bovino es un reservorio importante de variantes de $E$. coli patógenas de humano, y varios estudios han reportado que los patotipos de humano también están asociados con mastitis bovina(30-32). Por ejemplo, se han identificado diferentes arreglos de los genes $s t x_{1}, s t x_{2}$ y eaeA en $E$. coli aislada de mastitis bovina ${ }^{(30)}$. También se han descrito aislados de $E$. coliasociados a mastitis que tienen el gen eae $A$ sólo o en combinación con otros genes de virulencia, pero esos aislados fueron negativos para $s t x_{1} 0$ $s t x_{2}{ }^{(32)}$. Aunque muchos de los genes identificados en $E$. coli aislada de mastitis bovina no son específicos para la enfermedad, se ha sugerido que esos y otros elementos aun no identificados pueden ser responsables de la mastitis ${ }^{(6)}$. En este sentido, varios estudios se han enfocado en la asociación de factores de virulencia específicos de $E$. coli causante de mastitis, pero no lo han logrado $(6,33,34)$.

Normalmente, para el control de la mastitis bovina se emplea la terapia con antibióticos; sin embargo, muchas veces el tratamiento falla debido al incremento en la resistencia bacteriana a los antimicrobianos $^{(10)}$. En este sentido, las $E$. coli aisladas de mastitis bovina han desarrollado resistencia a los antibióticos comúnmente usados en medicina veterinaria para tratar la enfermedad(35). En este estudio se encontraron elevados niveles de resistencia para tetraciclina (88.2\%), ampicilina $(76.5 \%)$ y cefalotina $(73.5 \%)$, principalmente. Lo anterior puede estar relacionado con el hecho de que esos compuestos pertenecen a los principales grupos de antibióticos usados para el tratamiento de infecciones en ganado o se utilizan como promotores de crecimiento animal(36). En este sentido, se ha encontrado que $E$. coli aislada de mastitis bovina presentó resistencia a ampicilina (47.1 \%), kanamicina $(37.1 \%)$ y estreptomicina $(32.9 \%)^{(7)}$. Mientras que otros autores han encontrado altos índices de resistencia a ampicilina (98.4 \%), estreptomicina (40.3\%) sulfisoxazol (34.1\%) y tetraciclina $(24.8 \%)$, además de otros antibióticos $^{(37)}$. Asimismo, $64.7 \%$ de las E. coli analizadas en este estudio fueron multirresistentes, ya que fueron resistentes a tres o más antibióticos. Datos similares se han reportado ${ }^{(10)}$, donde el análisis de 70 aislados de $E$. coli resistentes a los antibióticos mostró que el $62.8 \%$ fueron multirresistentes.

La resistencia bacteriana a los antibióticos es debida a la presencia de genes que le confieren la capacidad de tolerar esos compuestos a través de mecanismos como expulsión, modificación, entre otros. Asimismo, el ganado bovino se considera un reservorio de $E$. coli, las cuales frecuentemente tienen genes de resistencia a antibióticos que se pueden diseminar a través de los alimentos de origen animal(11). De acuerdo con lo anterior, en este estudio se encontraron genes que codifican para beta-lactamasas, tetraciclina y estreptomicina en el 79.4 \% de las $E$. coli aisladas de mastitis bovina y todas ellas presentaron resistencia o resistencia intermedia a esos antibióticos. Lo anterior demuestra que en el área de estudio de este trabajo, el ganado bovino es reservorio de bacterias resistentes a los antibióticos, con la alta prevalencia de genes de resistencia a los antibióticos y que aunado a la presencia de genes de virulencia, representa un riesgo a la salud por la contaminación de la leche. Otros autores han encontrado genes para BLEE en el 26 y $1.5 \%$ de enterobacterias aisladas de excremento y leche de vacas con mastitis, respectivamente. En ese trabajo, se

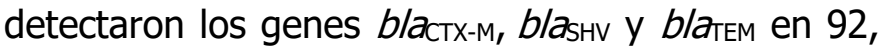
5.5 y $2.2 \%$ de las bacterias positivas para BLEE ${ }^{(38)}$. Además, diversos estudios han encontrado que $E$. coli multirresistentes causantes de mastitis contienen los genes blactx-м y blatem ${ }^{(39,40)}$.

También, el análisis genético de los determinantes de resistencia a tetraciclina $y$ estreptomicina en $E$. coli aislada de mastitis bovina, reveló que todas contenían uno o más genes de resistencia a esos compuestos en diferentes 
combinaciones $^{(37)}$. Además, en 33 E. coli analizadas en este trabajo presentaron al menos un plásmido grande (>50 kb, datos no mostrados), sugiriendo que los genes de resistencia pueden estar asociados con estos. De acuerdo con lo anterior se ha asociado a plásmidos $>35 \mathrm{~kb}$ con la presencia y movilización de genes de resistencia a antibióticos $^{(41)}$. Además, dos aislados presentaron integrones clase 1, cuya presencia se correlaciona comúnmente con aislados multirresistentes, sugiriendo que los genes pueden estar asociados a esos elementos. La asociación de genes de resistencia con integrones ha sido observada en otros estudios de $E$. coli causante de mastitis con altos índices de resistencia a los antibióticos ${ }^{(42)}$.

\section{CONCLUSIONES E IMPLICACIONES}

Se aislaron e identificaron $E$. coli asociadas a mastitis bovina y resistentes a antibióticos; aunque en baja frecuencia, éstas contienen genes de virulencia relacionados con patógenos entéricos de humano. También presentaron genes responsables de la resistencia a compuestos beta-lactámicos, tetraciclina, estreptomicina y quinolonas. Hasta donde se sabe, ésta es la primera vez que se determina la presencia de dichos genes de resistencia a antibióticos en $E$. coli asociada a mastitis bovina en México. Aunque se requieren más estudios para caracterizar el repertorio de genes de virulencia y de resistencia e investigar su movilidad por su posible asociación con plásmidos conjugativos. El estudio de las principales características de las bacterias patógenas asociadas a mastitis bovina, en el futuro podría contribuir a mejorar la situación de la enfermedad en los hatos ganaderos del estado, así como los riesgos a la salud asociados.

\section{AGRADECIMIENTOS}

Se agradece a Carlos Cervantes y Jesús Silva los comentarios al presente trabajo. Este trabajo fue financiado en parte por el apoyo del programa de desarrollo profesional docente (PRODEP), Fortalecimiento de Cuerpos Académicos (proyecto IDCA-11106) y por la Universidad de La Ciénega del Estado de Michoacán de Ocampo (UCEM).

\section{LITERATURA CITADA}

1. Seegers H, Fourichon C, Beaudeau F. Production effects related to mastitis and mastitis economics in dairy cattle herds. Vet Res 2003;34(5):475-491.

2. Thompson-Crispi $\mathrm{K}$, Atalla $\mathrm{H}$, Miglior $\mathrm{F}$, Mallard BA. Bovine mastitis: Frontiers in immunogenetics. Front Immunol 2014;5:1-10.

3. Contreras GA, Rodríguez JM. Mastitis: comparative etiology and epidemiology. J Mammary Gland Biol Neoplasia 2011;16(4):339356.

4. Kaper JB, Nataro JP, Mobley HL. Pathogenic Escherichia coli. Nat Rev Microbiol 2004;2(2):123-140.

5. Shpigel NY, Elazar S, Rosenshine I. Mammary pathogenic Escherichia coli. Curr Opin Microbiol 2008;11(1):60-65.

6. Blum SE, Leitner G. Genotyping and virulence factors assessment of bovine mastitis Escherichia coli. Vet Microbiol 2013;163(34):305-312.

7. Liu Y, Liu G, Liu W, Ali T, Chen W, Yin J, et al. Phylogenetic group, virulence factors and antimicrobial resistance of Escherichia coli associated with bovine mastitis. Res Microbiol 2014;165(4):273277.

8. Blum SE, Heller ED, Sela S, Elad D, Edery N, Leitner G. Genomic and phenomic study of mammary pathogenic Escherichia coli. PLoS One. 2015;10(9):1-24.

9. Hogan J, Larry Smith K. Coliform mastitis. Vet Res 2003;34(5):507519.

10. Saini V, McClure JT, Léger D, Keefe GP, Scholl DT, Morck DW, et al. Antimicrobial resistance profiles of common mastitis pathogens on Canadian dairy farms. J Dairy Sci 2012;95(8):4319-4332.

11. Phillips I, Casewell M, Cox $T$, De Groot B, Friis $C$, Jones $R$, et al. Does the use of antibiotics in food animals pose a risk to human health? A critical review of published data. J Antimicrob Chemother 2004;53(1):28-52.

12. Li $X Z$, Mehrotra M, Ghimire S, Adewoye L. beta-Lactam resistance and beta-lactamases in bacteria of animal origin. Vet Microbiol 2007;121(3-4):197-214.

13. Jacoby GA, Munoz-Price LS. The new beta-lactamases. N Engl J Med 2005;352(4):380-391.

14. Bush K, Jacoby GA. Updated functional classification of betalactamases. Antimicrob Agents Chemother 2010;54(3):969-976.

15. Nguyen $F$, Starosta AL, Arenz $S$, Sohmen D, Dönhöfer A, Wilson DN. Tetracycline antibiotics and resistance mechanisms. Biol Chem 2014;395(5):559-575

16. Sunde $M$, Norström $M$. The genetic background for streptomycin resistance in Escherichia coli influences the distribution of MICs. J Antimicrob Chemother 2005;56(1):87-90.

17. Gillings MR. Integrons: past, present, and future. Microbiol Mol Biol Rev 2014;78(2):257-277.

18. Scheutz F, Strockbine N. Escherichia. Bergey's Manual of Systematics of Archaea and Bacteria. 2015:1-49.

19. Madico G, Akopyants NS, Berg DE. Arbitrarily primed PCR DNA fingerprinting of Escherichia coli $\mathrm{O} 157: \mathrm{H} 7$ strains by using templates from boiled cultures. J Clin Microbiol 1995;33(6):1534-1546.

20. Horakova K, Mlejnkova $H$, Mlejnek P. Specific detection of Escherichia coli isolated from water samples using polymerase 
chain reaction targeting four genes: cytochrome bd complex, lactose permease, beta-D-glucuronidase, and beta-Dgalactosidase. J Appl Microbiol 2008;105(4):970-976.

21. Vidal M, Kruger E, Durán C, Lagos R, Levine M, Prado V, et al. Single multiplex PCR assay to identify simultaneously the six categories of diarrheagenic Escherichia coli associated with enteric infections. J Clin Microbiol 2005;43(10):5362-5365.

22. Ahmed AM, Shimamoto T. Molecular characterization of multidrugresistant avian pathogenic Escherichia coli isolated from septicemic broilers. Int J Med Microbiol 2013;303(8):475-483.

23. Guillaume G, Verbrugge D, Chasseur-Libotte M, Moens W, Collard J. PCR typing of tetracycline resistance determinants (Tet A-E) in Salmonella enterica serotype Hadar and in the microbial community of activated sludges from hospital and urban wastewater treatment facilities in Belgium. FEMS Microbiol Ecol 2000;32(1):77-85.

24. Gebreyes WA, Altier C. Molecular characterization of multidrugresistant Salmonella enterica subsp. enterica serovar Typhimurium isolates from swine. J Clin Microbiol 2002;40(8):2813-2822.

25. Robicsek A, Strahilevitz J, Sahm DF, Jacoby GA, Hooper DC. qnr prevalence in ceftazidime-resistant Enterobacteriaceae isolates from the United States. Antimicrob Agents Chemother 2006;50(8):2872-2874.

26. Mazel D, Dychinco B, Webb VA, Davies J. Antibiotic resistance in the ECOR collection: integrons and identification of a novel aad gene. Antimicrob Agents Chemother 2000;44(6):1568-1574.

27. CLSI. Methods for dilution antimicrobial susceptibility tests for bacteria that grow aerobically. Ninth ed. Approved Standard M07A9. Clinical and Laboratory Standards Institute. 2012.

28. Blum SE, Heller ED, Leitner G. Long term effects of Escherichia coli mastitis. Vet J 2014;201(1):72-77.

29. Momtaz H, Safarpoor Dehkordi F, Taktaz T, Rezvani A, Yarali S. Shiga toxin-producing Escherichia coli isolated from bovine mastitic milk: serogroups, virulence factors, and antibiotic resistance properties. Scient World J 2012;2012:1-9.

30. Kobori D, Rigobelo EC, Macedo C, Marin JM, Avila FA. Virulence properties of Shiga toxin-producing Escherichia coli isolated from cases of bovine mastitis in Brazil. Revue d'élevage et de medcine vétérinaire des pays tropicaux 2004;57(1-2):15-20.

31. Lira WM, Macedo C, Marin JM. The incidence of Shiga toxinproducing Escherichia coli in cattle with mastitis in Brazil. J Appl Microbiol 2004;97(4):861-876.
32. Suojala $L$, Pohjanvirta $T$, Simojoki $H$, Myllyniemi AL, Pitkälä $A$ Pelkonen S, et al. Phylogeny, virulence factors and antimicrobial susceptibility of Escherichia coli isolated in clinical bovine mastitis. Vet Microbiol 2011;147(3-4):383-398.

33. Fernandes JB, Zanardo LG, Galvão NN, Carvalho IA, Nero LA, Moreira MA. Escherichia coli from clinical mastitis: serotypes and virulence factors. J Vet Diagn Invest 2011;23(6):1146-1152.

34. Kaipainen T, Pohjanvirta T, Shpigel NY, Shwimmer A, Pyörälä $S$, Pelkonen S. Virulence factors of Escherichia coli isolated from bovine clinical mastitis. Vet Microbiol 2002;85(1):37-46.

35. Suojala L, Kaartinen L, Pyörälä S. Treatment for bovine Escherichia coli mastitis - an evidence-based approach. J Vet Pharmacol Ther 2013;36(6):521-531.

36. Dibner JJ, Richards JD. Antibiotic growth promoters in agriculture: history and mode of action. Poult Sci. 2005;84(4):634-643. doi: $10.1093 / \mathrm{ps} / 84.4 .634$.

37. Srinivasan V, Gillespie BE, Lewis MJ, Nguyen LT, Headrick SI, Schukken $\mathrm{YH}$, et al. Phenotypic and genotypic antimicrobial resistance patterns of Escherichia coli isolated from dairy cows with mastitis. Vet Microbiol 2007;124(3-4):319-328.

38. Geser N, Stephan R, Hächler H. Occurrence and characteristics of extended-spectrum $\quad \beta$-lactamase (ESBL) producing Enterobacteriaceae in food producing animals, minced meat and raw milk. BMC Vet Res 2012;8(1):1-9.

39. Pehlivanoglu F, Turutoglu H, Ozturk D. CTX-M-15-Type ExtendedSpectrum Beta-Lactamase-Producing Escherichia coli as causative agent of bovine mastitis. Foodborne Pathog Dis 2016;13(9):477482.

40. Timofte D, Maciuca IE, Evans NJ, Williams H, Wattret A, Fick JC, et al. Detection and molecular characterization of Escherichia coliCTXM-15 and Klebsiella pneumoniae SHV-12 $\beta$-lactamases from bovine mastitis isolates in the United Kingdom. Antimicrob Agents Chemother 2014;58(2):789-794.

41. Freitag C, Michael BG, Kadlec K, Hassel M, Schwarz S. Detection of plasmid-borne extended-spectrum $\beta$-lactamase (ESBL) genes in Escherichia coli isolates from bovine mastitis. Vet Microbiol 2017;200:151-156.

42. Wang GQ, Wu CM, Du XD, Shen ZQ, Song LH, Chen X, et al. Characterization of integrons-mediated antimicrobial resistance among Escherichia coli strains isolated from bovine mastitis. Vet Microbiol 2008;127(1-2):73-78. 